\title{
A Strategy for Consumer Protection in Pakistan
}

\author{
KISHWAR KHAN and SARWAT MANSOOR
}

\begin{abstract}
Government is relying increasingly on the market mechanism for economic management. The underlying perfect competition model assures maximum welfare of consumer, but assumptions of the model do not hold in real world. Consumer is central to economic activity but at the same time is vulnerable to exploitation by producers, misleading information, ignorance of his rights and non-availability of redress mechanism. Markets may be competitive but the consumers may suffer on account of imperfect information, search and transport costs needed to make satisfactory choices. This creates the need for government intervention for protecting the consumer welfare and rights. This paper explains why a consumer protection policy is needed in a situation of 'competitive' markets and looks into consumer protection strategies followed in some other countries. The area of consumer protection in Pakistan has remained neglected so far and no meaningful effort has been made in this direction. Realising this gap, the paper chalks out a consumer protection strategy for Pakistan; which goes beyond mere formulation of legislation and also includes consistent efforts towards awareness creation, provision of information/advice, setting of quality standards and redress. In the long run the efforts should continue in the from of research, formation/strengthening of consumer pressure groups and regional cooperation.
\end{abstract}

\section{INTRODUCTION}

Increased reliance is being placed on forces of competition as a factor in economic management. This paper explores why a consumer protection policy is needed in a situation of ostensibly competitive market and presents consumer protection strategies followed in some countries. It also sets out a consumer protection strategy for Pakistan. The basic aims and objectives of the consumer protection exercise are spelled out. Future policy requirements, both short-term and long-term, in protecting consumers are identified.

The paper is divided into four sections. Section I provides a discussion on the theoretical background covering relevant aspect of the perfect competition model, the failure of which gives rise to issues of consumer protection. The model is a useful thinking device but differs from actual consumer experience. Competition purportedly maximises consumer welfare, the markets may be 'competitive' but the consumers may

Kishwar Khan is Assistant Director (R \& I), Monopoly Control Authority, Islamabad. Sarwat Mansoor is Research Officer, Monopoly Control Authority, Islamabad.

Authors' Note: The views expressed in the paper are of the authors' and in no way relate to those of the Monopoly Control Authority. 
suffer on account of instances of market failure, e.g., imperfect information and search and transport costs in making satisfactory choices. Consumers thus need effective ways to redress the situation so that signals are sent back to the suppliers for providing the desired goods or services; signals that market failure may deny. Market failure creates the need for government intervention for protecting the consumers' welfare, as envisaged in principle in the perfect competition model. In this manner the paper examines the implications for the consumer of relaxing the assumptions of the perfect competition model.

Section II gives the experiences of some other countries in the area of consumer protection, which covers efforts made at the governmental level by the respective consumer protection authorities. Section III discusses the efforts made by Pakistan thus far; these include the present Islamabad Act on Consumer Protection. The section discusses the salient features of Islamabad Consumer Protection Act. Section IV, the last section gives policy recommendations, delineating short-term and long-term measures.

\section{THE PERFECT COMPETITION MODEL AND ITS IMPLICATIONS FOR THE CONSUMER}

A market is said to be perfectly competitive, where (1) there are large number of independent sellers of a homogenous product, (2) an individual seller has no control over the price of the commodity as he sells a negligible portion of total output, and (3) the individual seller assumes the role of a price taker and sells his output at the prevailing market price and he may sell any quantity. The main assumptions and implications of perfect competition are as follows:

(a) Large number of buyers and sellers of an individual commodity, such that no single agent is in a position to dictate the terms based on either supply or demand.

(b) Homogeneous goods and perfect substitutability of the products which implies that consumers' preference is same for the output from all firms.

(c) Profit maximisation. In a perfectly competitive market a firm maximises its profit with reference to a given market price, established by the forces of demand and supply.

(d) Perfect knowledge on the part of buyers regarding price charged by any firm. Similarly, every producer is aware of the common production techniques of all other producers in the industry. The producer also has perfect knowledge regarding the taste (and changes in the taste) of the buyers. This is possible in a situation where there are no information costs.

(e) There are no transport costs or time costs for both the buyers and sellers.

(f) The businessmen have no power. 
(g) Base of entry and exit; the firms in a competitive market can easily enter or leave the industry in response to the economic forces.

(h) Perfect factor mobility and divisibility, the factors of production are perfectly mobile and divisible in a competitive model, there are no artificial restrictions on the prices or on the movement of factors. The resources are shiftable and mobile.

Consumers' interest are automatically taken care of under perfect competition. In terms of prices this comes from the fact that no seller can charge a price higher than that prevailing in the market. In addition, the products are homogeneous, hence in terms of quality, consumers' demand is satisfied by any firm's product. There are no costs related to transportation, information and time consumption. The buyer has a perfect knowledge of the market and his welfare is thus maximised.

Actual experience, however, presents a sharp contrast to this over simplified model. There are transport costs, knowledge imperfections, restrictions on the mobility of factors of production, barriers to entry and products are not homogeneous or perfect substitutes. Product differentiation is one of the important characteristics of imperfect competition. Products are differentiated by natural causes as well as man-made elements. Each firm tries to differentiate its product from the others by advertising, propaganda, attractive packaging, patents, etc. to have a monopolist-like position for the differentiated product.

In the absence of perfect competition, prices are influenced by producer/seller individually, or acting in a cartel, which could result in exploitation of the consumer. Another deviation from perfect competition is the exercise of monopoly power. Monopoly power implies the ability of one or few sellers to have control over the supply or price of the product. The market share of a firm determines its degree of dominance. Existence of a single firm leads to pure monopoly. In an oligopolistic setup, one or more firms may be monopolistic.

Monopolistic actions ultimately result in the exploitation of the consumers. The consumers may have to pay a higher price than in case of competition. Due to increased price some consumers cannot use the product because of their limited purchasing power. Secondly, if the monopolist restricts output in case of commodities having inelastic demand then all possible users may not get the product. Thirdly, if the demand elasticity of a product does not allow a price increase, the producer may opt to compromise quality, hence consumers get a sub-standard product. This is why monopolistic practices are considered detrimental to the public interest.

The imperfections of the market call for some mechanism to protect the interests of consumers; competition and consumer protection authorities fulfil this task. Competition could be brought about by lessening the barriers to entry, effective distribution channels, and by controlling unreasonable monopoly power. Different 
legislations such as those relating to standardisation, packaging and branding, food adulteration, hoarding, etc., address the well-being of consumers and, at a conceptual level, cater to the inadequacies of the perfect competition model. Such laws, in fact, prove to be insufficient for the purpose of providing redress to the consumers as the procedures are complex, cumbersome and time consuming, while the remedies are limited in scope. Against this background, the consumer protection authority (CPA) serves as a regulator and sometimes also acts as an arbitrator. Its aim is to protect consumer welfare, firstly, by the provision of correct and adequate information to the consumer, at the right time. Secondly, The CPA could intervene in the redress process by making such processes accessible, speedy and effective. In cases of extreme violation of standards such as in terms of quality, the supplier/producer could be made to quit the market and in other less severe cases fines/punishments could also be used.

Some of the problems faced by the consumers and the corresponding action of the CPA is explained below with the help of diagrams. Six hypothetical situations of monopoly, monopolistic competition, product differentiation, time and distance related costs, and imperfect knowledge about prices on the part of consumers are explored to see the impact of actions by a CPA.

Figure 1 shows the case, where the monopolist charges a higher price in the absence of CPA, i.e., OP. The action by CPA and consumer pressure groups create awareness by publicising the unreasonable practice of monopolist, which pushes down the demand curve of the product on the one hand and forces the monopolist to reduce the unreasonable price on the other. The profit margins, are thus reduced after CPA intervention, from P“PKL to P“P`MN. In Figure 2 the monopolist is bound by the consumer pressure groups, to reduce price to $\mathrm{OP}^{`}$; at a level where marginal cost equates average cost.

Figure 3 shows that under situation of monopolistic competition, the CPA would not allow the seller to reap unreasonable profit i.e., PP` LM. Hence, the reduced price OP` will force seller to sell more i.e. OQ` in order to maximise his profit.

In situations of imperfect competition, the producer spends heavily on advertising to differentiate the product from that of the competitors'. In Figure 4 below the supply curve shifts to $S^{`}$ due to capacity utilisation and the demand curve shifts to $D^{`}$ as a response to advertising effort to differentiate the product. Hence, at the same price $\mathrm{P}$ the producer is able to sell more that is, OQ instead of OQ. With the intervention of the CPA, consumers are made aware of minor differentiation; the producer can still sell more i.e. OQ “ but at a relatively lower price i.e. OP’, and a lower level of quantity than before.

Figure 5 reflects a situation where a commodity is sold at different prices within the same city. The distance, time and transportation costs force a buyer at point "a" to buy an item at a higher price i.e. $P$ instead of going to the point " $d$ " and getting the same product at a cheaper price i.e. P`. The CPA makes known the price differentials. As a 


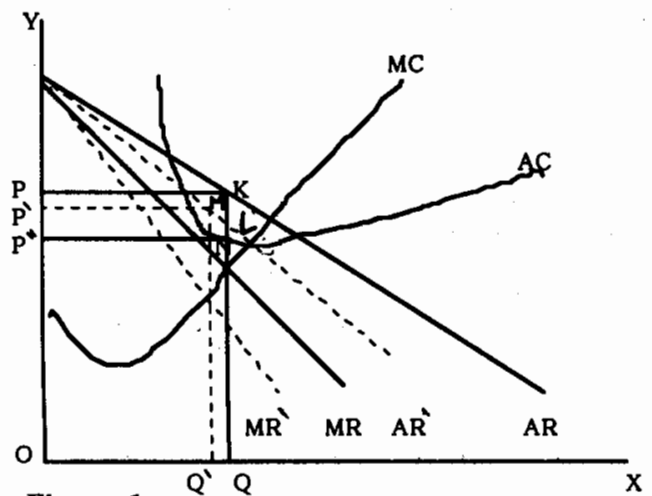

Figure 1.

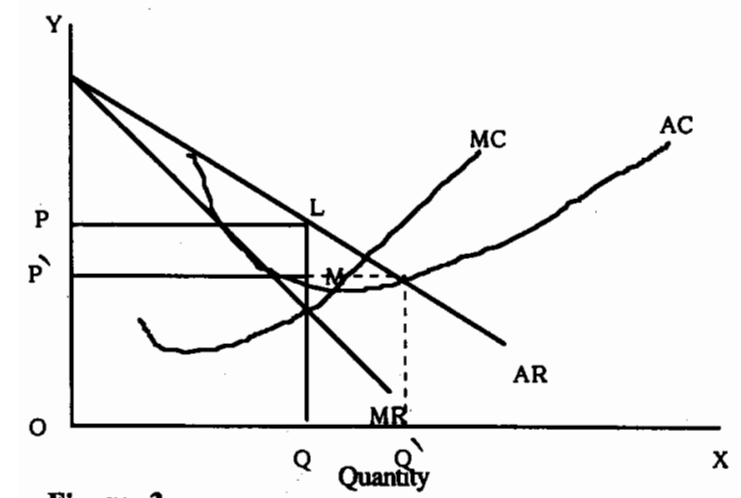

Figure 3.

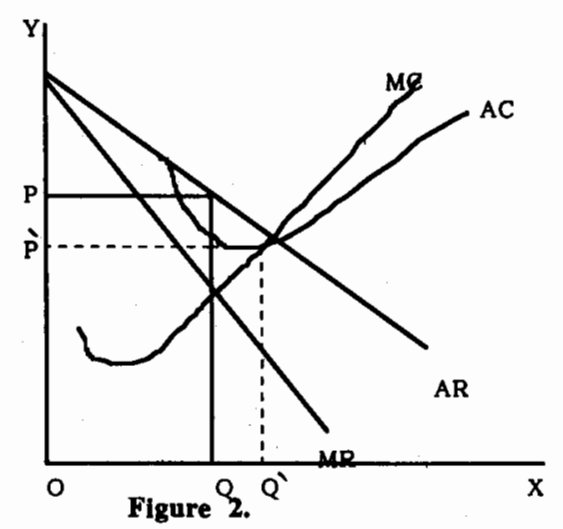

Figure 2.

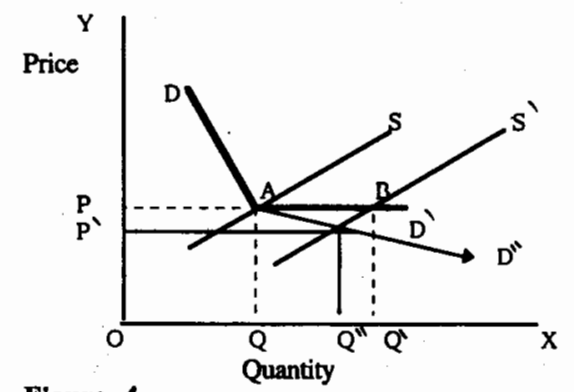

Figure 4. 


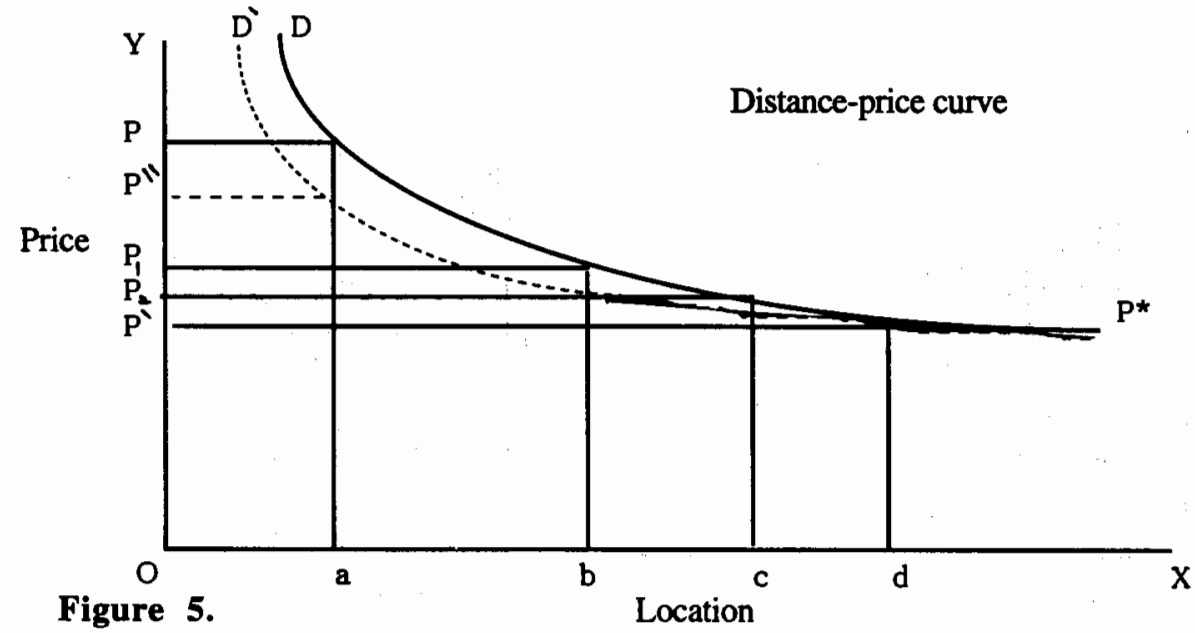

result the demand curve shifts from DP* to D'P*. This intervention forces the seller to sell the product at a relatively comparable price, thus shifting the price from $\mathrm{P}$ to $\mathrm{P}^{\prime \prime}$ at "a".

In Figure 6. knowledge imperfections are reduced as the CPA makes the price differentials known. Consequently, the prices in different markets are set to a comparable level.

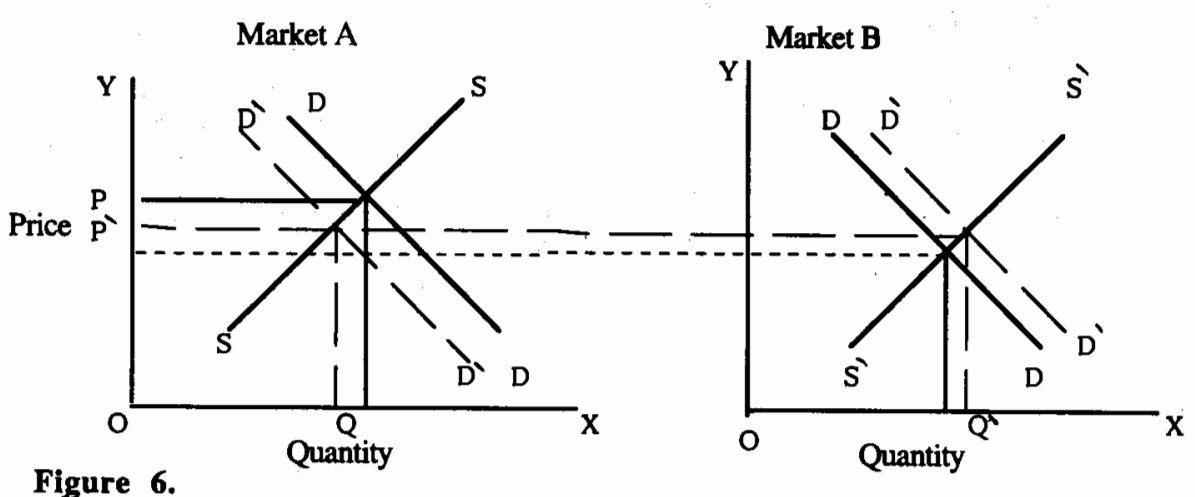

Figure 6. 
It is clear from Figure 6 that due to imperfect knowledge on the part of buyers, the sellers are able to charge different prices. This situation can no longer be maintained if they are well informed of market situations. The result would be a decline in the prices in the market $\mathrm{A}$ and an increase in the price at market $\mathrm{B}$ i.e., $\mathrm{P}$.

Apart from Figures 1 and 2, others reflect issues arising due to nonavailability/inadequate information. This information gap is filled by CPA.

\section{EXPERIENCE OF OTHER COUNTRIES IN THE AREA OF CONSUMER PROTECTION}

To protect the consumers, different countries (the respective laws of Australia, Germany, India, Sri Lanka and United Kingdom were studied) have adopted different measures, which primarily aim at provision of information and redress mechanisms alongwith improving prospects of competition and efficiency. The respective competition and consumer protection authorities are playing an important role in this respect. ${ }^{1}$

The main objective of the authorities in the 6 countries is to protect and promote consumer rights which include, firstly, the right to be informed about the quality, quantity, potency, purity, standard and price of the goods. In this regard, the Office of Fair Trading (OFT) in UK provides several consumer advice publications. These include: Your shopping rights, Prepayments, Buying a service, Using an Estate Agent to Buy or Sell Your Home, etc. to educate the consumers about their rights. In Sri Lanka, the Department of Internal Trade (DIT) issues "Directions" for labelling, price marking, packeting, etc., or special directions may be given for manufacturing, marketing or sale of articles. In Germany, 250 regional centres are working to provide consumers with advice and information. Secondly, the right of the consumers to be protected from hazardous goods. For instance, in Germany, the Stiftung Warentest tests all the products with a wide range e.g., ball-point pens to the personal computers. Products are tested for their quality, value for money and compatibility with the environment (services are also tested). Warentest call upon only independent experts and institutions. Due to its independent opinion it has gained a good reputation both from the consumers and producers, it gives producers an advertising advantage as being approved by the Warentest. Thirdly, consumers have the right of redress. In Australia, for instance, the Australian Competition and Consumer Commission (ACCC), may sue a manufacturer for defective goods on behalf of one or more persons who have suffered loss, providing those persons give written consent for the ACCC to act on their behalf. The consumers

${ }^{1}$ Although the purpose of this paper is not to assess the strengths and weaknesses of the consumer protection work of the authorities in the respective countries. However, as a brief reference some of the problems faced by the authorities include, lack of uniformity in the procedures in different organisations dealing with consumer protection within the country, lack of financial and human resources to detect misleading conduct, false representation, anti-competitive practices, etc. 
are entitled to compensation if the goods they buy are not of merchantable quality, are not fit for their purpose, do not match the description or sample, have defects, the spare parts and repairs for the product are not available, etc. The consumers are entitled to complain and procure redress. The redress guidelines by DIT in Sri Lanka, provide that if the fault is in no way connected with the customers own mishandling of an article, it will be immediately returned to the trader, as any undue delay may cause problems pertaining to liability. The customers are required to retain all relevant documents whenever an article is purchased and may request redress which can take the form of repairs, replacements, refund of cash, compensation, etc. The consumer has the right to complain directly to the Consumer Redress Division of the DIT. In India, quasi-judicial bodies at district, state and national level are set up under Consumer Protection Act (COPRA) for speedy compensation of consumer's complaints. These bodies have powers of a civil court to facilitate the availability of necessary documents and examination under oath. The District Consumer Disputes Redressal Forums (DCDRFs) have a pecuniary jurisdiction of Rs 5 lakh. and the State Commissions has Rs 20 lakhs limit. In case exceeds the compensation amount accedes Rs 20 lakhs the consumer has to apply to the National Commission. ${ }^{2}$ The decisions of the authority are however subject to appellate and revision jurisdictions.

Last but not least, the consumers have the right to being educated. This is necessary due to the ever increasing number of new products in the market. This variety and increased choice creates problems for the consumers to judge the quality of products, dishonest sales methods or dangers to health. In Germany, the results of tests are publicised by the Warentest in its monthly publications 'test' and 'FINANZ - Test', which have a circulation of about a million. The results are also regularly publicised in 160 newspapers and periodicals, and on radio and television.

From the above discussion, it can be summarised that the thrust of the effort of competition and consumer protection authorities is to adequately inform the consumers and promote conditions of competitiveness. However, the economic, social and legal environment differs across countries and an effective policy in one country may not prove equally effective in another.

\section{EFFORTS MADE BY PAKISTAN FOR CONSUMER PROTECTION}

\section{Islamabad Consumer Protection Act}

The policies of the Government of Pakistan regarding economic liberalisation, deregulation and privatisation and the subsequent expansion of the private sector rely on

${ }^{2}$ Country papers of Sri Lanka and India on 'Socio-economic Implications of the World Trade Agreement of South Asian Countries’. September 11-12, 1995. Regional Seminar, Bangladesh, organised by Friedrich Ebert Foundation, Islamabad. 
the efficient working of market processes and also improvement/promotion of such processes. It is natural therefore to provide a regulatory framework that addresses the issues arising from likely market failures. This has led to the need for enacting appropriate legislation to safeguard the interests of the consumers. Indeed, under Article 18 of the Constitution, it is the duty of the state to regulate trade, commerce or industry in the interest of free competition. To protect the rights of the consumers in situations of inadequate information, impediments in competitive behaviour in the markets, the Federal Government enacted the Islamabad Consumer Protection Act on October 18, 1995. This law incorporates definitions of unfair trade practices as well as provides for a mechanism for handling consumer complaints.

The definition of unfair trade practice aims to identify situations where either insufficient, misleading or false information in respect of the product has been provided to the consumer. The examples are any false information/advertisement regarding quality, quantity, grade, composition, style or mode, or rebuilt, reconditioned or old goods shown as new goods, false warranty or guarantee of performance, facilities available in the private educational institutions, professional services, etc. Furthermore situations restrictive of competitive behaviour such as hoarding and black-marketing are also defined as unfair trade practices. Safety concerns are also addressed and trade practices that cause loss or injury through adulteration, selling of expired drugs, food items and commodities unfit for human consumption are also defined as unfair. Finally, charging for goods and services in excess of the prices fixed by an authority authorised to do so, is prohibited under the legislation.

The mechanism for handling consumer complaints works as follows. The law provides for a Consumer Protection Council in Islamabad which will consist of prominent citizens involved in social work as well as legislators and government officials. The main purpose of the Council shall be to inform the consumers about their rights. Also the purpose includes to determine, promote, protect and formulate policies for the interests of the consumers against marketing of hazardous goods, variety of goods/substitutes at competitive prices, compensation against unfair trade practices of unscrupulous exploitation of consumers, easy availability of essential services and right of information about the quality, quantity, purity, standard and price of goods and services. To ensure this the Council shall coordinate between the Government, manufacturers, producers, suppliers and consumers. To adjudicate disputes the law sets up an Authority which according to the Islamabad Act shall be the Court of Sessions. The Council or the consumer can file a complaint to the Authority against any unfair trade practice. If the Authority observes that the rights of the consumers have been infringed, it shall first provide the opportunity of being heard to the relevant parties. If the rights of the consumers are found to be violated, the Authority may punish the person responsible with imprisonment which may extend to two years or with fine which may extend to forty thousand rupees, or with both. Similar punishment may be 
given to a person responsible for false or misleading advertisement. The Authority may order for payment of compensation to the consumer to the extent the consumer has suffered any damage or loss through any unfair trade practice. The Authority can also order for confiscation of the goods or direct for their destruction. ${ }^{3}$

The present consumer protection law is only for the Federal Capital. Consumer protection being a provincial subject the provinces are also in the process of formulating legislation for their respective provinces, Islamabad Consumer Protection Act is being used as a model law for this purpose. ${ }^{4}$

\section{POLICY RECOMMENDATIONS}

The first step in this respect is the precise categorisation of the tasks which may fall within the consumer protection work, and the definition of the overall boundaries of such work, is of utmost importance. This certainly is not a straightforward thing to start with. In the short term, effective enforcement and execution involves five tasks.

First is the need for appropriate legislation for consumer protection. Appropriate legislation for consumer protection should be enforced in the whole country. It should cater to the peculiarities of the market situations. The legislation should aim at reducing information gaps, providing advice and redress to the best of consumer interests. At the same time there is a need to create awareness amongst the consumers and to inform them of their rights.

Secondly, raising general awareness at both government as well as general public level is necessary. Government should be conscious of the fact that protecting the rights of the consumers is essential for promoting efficient and effective competition in the country. The Islamabad Consumer Protection Act is the first step in this direction and its extension to the provinces will prove to be a bigger challenge. General public on the other hand, being consumers, should be made aware of their rights. Tripartite seminars, having participation from consumers, industry and the government with involvement of mass media could be used for this purpose. Publicity campaigns by the consumer associations and NGOs can also prove helpful in this regard.

\footnotetext{
${ }^{3}$ Some important issues which need attention, once the law is operational are: firstly, suitable laboratories for testing the quality of the products, secondly, registration of consumer protection associations, thirdly, time-frame to be specified within which a complaint can be filed so that consumer do not misuse the law, fourthly, frivolous complaints should be disposed of at the earliest possible stage to minimise costs, fifthly, instead of confining the law to prosecution only, there should be provision for replacement or removal of defect in a product, last but not least, the law should also cover the issues of environment protection. Moreover, the UN Guidelines for Consumer Protection, 1985, can also be used as a checklist against which the effectiveness of policies can be measured.

${ }^{4}$ Shamim A. Rizvi, "MCA: The Consumer-friendly dragon awakens!” Pakistan and Gulf Economist, August 3-9, 1996. pp. 38-41.
} 
Thirdly, is the issue of adequate information and advice in more specific terms. Information can serve as an effective tool for consumer protection in many ways; firstly, well informed consumers would be in a better position to protect themselves against exploitation; secondly, even in case of problems, they would be able to resolve by themselves; thirdly, where they are unable to do so, they will be able to get assistance from others. This should be the essential element of any consumer protection agenda. A wide range of small, attractive and precise booklets having facts about goods and services should be provided at convenient places to inform the consumers.

Guidance and advice should be provided to consumers on individual case bases in response to telephonic/written queries. Regulation on information should be formulated to outlaw misleading information about products. It may be by means of legislation e.g., on trade descriptions and misleading advertisement as well as prescribing what should be revealed in the interest of consumers. Improved disclosure of information may be used as a remedy for situations of consumer impairment.

Fourthly, there is the need to lay down quality standards to provide minimum specifications for goods and services to be sold. Quality, used in a wider meaning, may cover weights and measures legislation, safety regulation, some other measures which may be product specific e.g., food hygiene, etc. The objective behind this task is to impart a sense of confidence to the consumer in making choices. However, it should be assured that quality standards and procedures required thereof are maintained with least burden on suppliers/producers. Producers and traders should also be advised by the CPA regarding their benefits in complying with the quality and information standards. This would help reduce difficulties at both consumers' and producers' end.

Fifthly, it is important to secure speedy redress; this should be provided through courts such as small claim courts, session courts, ombudsman and other self regulatory mechanisms e.g., guarantees and arbitration schemes. The objective is to encourage more effective and accessible redress channels for all, which may be used when other measures for consumer protection might not impede consumer exploitation.

In the long-term there is need to create an appropriate environment for execution and enforcement. There are five aspects: First, research on other countries legislations by the academicians and other consumer representative bodies (e.g., consumer NGOs) into the matters related to consumer protection should be conducted on continuous basis. The procedures/processes followed in other countries while dealing with cases of consumer protection and the ways to effectively use/accommodate them in Pakistan's legislation should be analysed. The results of research and investigations into areas of consumer concern, identification of core issues on specific sectors/trading practices, with recommendations should be directed to industry/government. The results should also be publicised for the benefit and knowledge of general consumers.

Formation of and lobbying by consumer pressure groups is the next task. The groups should pursue recommendations derived both through actual experiences and 
research work for changes in the existing practices adversely affecting interest of the consumers. This may be in the shape of providing policy inputs and representations. The existence of such groups in an effective capacity would go a long way in strengthening the consumer's position. ${ }^{5}$ Producers involved in malpractices will fear the negative publicity that the consumer pressure groups may give about their product or company and thus may resort to fair trade. The task of the Consumer Protection Agencies would be considerably lessened.

Third is the formulation/revision of policy and legislation, essentially to be done by the Government by way of policy-making. Time to time revision of legislation should be done in light of results of research and recommendations by the consumer groups. Public interest groups should be consulted and briefed at every stage of legislative changes. This will help in receiving appropriate inputs from the consumers regarding the necessary changes and in keeping active involvement of the public. The efforts should be towards development of an integrated consumer protection policy such that different branches of the government maintain appropriate consumer dimension while taking any step or decision which will affect consumers.

Fourthly, coordination should be assured among CPA, Council and consumer organisations/groups and their roles/functions be clearly defined. Otherwise the possibility of overlaps in efforts, or gaps in coverage, may arise.

Fifthly, regional cooperation among SAARC/ASEAN countries could be developed in the form of setting up an International/Regional Supervision Network. This Network could help in dealing with cross-border consumer complaints and inquiries can be referred to the appropriate authorities in other countries through the auspices of the Network. In addition, it would help Pakistan to benefit from the experiences of other countries.

\section{CONCLUSIONS}

The perfect competition model differs from the actual experience of the consumers. This is due to the fact that the assumptions of the model e.g., perfect knowledge, zero cost, etc., are not valid in the real world. The information and awareness gaps on the part of consumers while making choices and misleading/false information provided by the producers necessitates the need for CPA. The paper explains the need for CPA in terms of the analysis of market structure models. CPA serves as an intermediary and as an arbitrator in different countries of the world. Experiences of Germany, UK, Australia, Sri Lanka and India are discussed briefly as in Pakistan the efforts towards consumer protection have remained limited thus far.

\footnotetext{
${ }^{5}$ Some consumers' groups active in Pakistan include Network Association for the Rational Use of Medicine, Lahore-based Consumer Watch, Saarif Mahaz and Punjab Lok Sujag. However, these groups have a low profile and their activities have not generated the momentum needed to start a broad level consumer movement.
} 
A strategy for consumer protection in Pakistan would involve firstly, an appropriate legislation for consumer protection for the entire country. However any formulation of legislation per se is not sufficient without assuring its effective implementation. For instance, Islamabad Consumer Protection Act has been enacted for a year now but still the Consumer Protection Council has not been formed nor has the Law been given proper publicity and even the consumers of Islamabad are unaware of this Law. Among other components of strategy are, awareness creation, provision of information/advice, setting of quality standards and provision of speedy redress, in the short run. The long term tasks world include research, formation of consumer pressure groups and regional cooperation in the area of consumer protection.

\section{REFERENCES}

A Status Report on Indian Policy and Legislation in the Fields of Economy, Consumer Protection and Environment Protection. Country paper presented in the Regional Seminar on the 'Socio-economic Implications of the World Trade Agreement South Asian Countries', September 11-12, 1995, Bangladesh, organised by Friedrich Ebert Foundation, Islamabad.

Islamabad Consumer Protection Act, October 18, 1995, The Gazette of Pakistan, Islamabad. 


\section{Comments}

The paper by Khan and Mansoor on "A Strategy for Consumer Protection in Pakistan” courageously addresses an important and emerging issue of consumer protection in Pakistan's goods market. It documents the role of consumer protection agencies in some developed or neighbouring developing countries. There can be no doubt that countries like Pakistan can learn from the experience of advanced industrialised countries in their consumer protection strategies. The information about the quality of products, maintenance of standards and redress mechanism can go a long way in protecting the genuine interests of the consuming public. However, this argument cannot be used to justify undue intervention of government regulatory agencies. In this era of deregulating economies, one should be careful in proposing new regulations. Although, consumer protection strategies aim at protecting people, yet producers are people too. To maximise overall welfare of society only economic theory and policy should serve as a guide. Therefore, it is desirable that the consumer protection agency should not be driven simply by rhetoric or casual empiricism.

In this perspective, let me acknowledge that I have found this paper interesting and informative. Drawing heavily on the figures in Section 1, the authors propose a consumer protection policy for Pakistan. The question remains, however, as to whether their conclusions are vested in standard economic theory and policy. Therefore, my comments below mainly focus on the theoretical consistency of the framework underlying their figures.

- In Figures 1 and 2, the authors claim that the consumer protection agency's (CPA) action and consumer pressure will force the monopolist to adopt average cost pricing rule as in Figure 2. The authors may want to elaborate on the mechanism how this system works and why?

- In Figure 3, the CPA not only forces average cost pricing (as in Figure 2) but also forces the seller to sell more, i.e., from OQ to OQ'. One can ask how the CPA may force producers of differentiated products (who sell thousands of products with different brand names) to charge average cost pricing. A more serious problem seems to be that the producers are selling where AC>P. It implies, in other words, that the CPA would force otherwise profit maximising producers to assume the role of inefficient and irrational profit minimisers.

- In Figure 4, the authors assert that advertising and capacity utilisation will shift demand and supply curves. However, it is unclear to me why the demand curve is kinked. If product differentiation through advertising gives price control to producers then the demand curve should be negatively sloped. Moreover, in advertising costs the distinction should be made between constructive (informative) and combative advertising because they have different 
implications on the direction of shift in demand curve. For example, constructive advertising may increase demand and therefore shift demand curve to its right. However, combative advertising merely reflects competition among different brands for a share in the fixed market. Consequently, combative advertisement is defensive in nature. Firms are sometimes forced to use combative advertisement to avoid losing market share since their rival firms are doing so. Therefore, combative advertising may increase or decrease the market share of an individual firm. Should the supply curve shift to its right as depicted in Figure 4? We know from economic theory that output supply is a function of output and input prices or $y(P, w, v)$. If supply curve shifts in response to advertising cost it should shift to its left instead of right as in the figure. Capacity utilisation is a factor which can shift supply curve to its right but it depends on the economies of scale. Even if capacity utilisation is recognised as a shift factor it may require overtime to workers at higher than normal rates. If it is so, even then the supply should shift to its left.

- The truth to the matter is that advertisement cost and overtime will shift the supply curve to its left while capacity utilisation or economies of scale may push supply curve to shift to right. The net effect may be ambiguous and may vary from one industry to another.

- In Figure 5, the authors explain a situation when a commodity receives different prices within the same city. Which market structure is assumed and how supply interacts with demand in this figure is not clear from the paper. I understand that price variation in different markets in the same city may be explained by different rents of shops or transport cost to sellers, which shift supply to its left or right.

Besides, there are several inconsistencies in the paper that needs to be dealt with. To quote just one example, in the second paragraph of the paper the authors note that "the markets may be competitive but the consumers may suffer on account of instances of market failure". My question is: If market fails, can we really call that market perfectly competitive?

I sincerely feel that the authors can make a case for consumer protection and welfare by discussing the dead weight loss associated with monopoly market structure. They should discuss the role of CPA for the cases of natural monopolies such as utility companies and should also comment on how we can make use of the information on consumer demand elasticities?

Quaid-i-Azam University,

Abid A. Burki

Islamabad. 